\title{
Vicarious trauma inside the academe: understanding the impact of teaching, researching and writing violence
}

\author{
Andrea Nikischer ${ }^{1}$ (iD
}

Published online: 24 August 2018

(C) Springer Nature B.V. 2018

\begin{abstract}
Myriad research has found a relationship between working with potentially distressing situations and content, such as that related to child sexual abuse, sexual assault and domestic violence, and the experience of vicarious traumatization and/or compassion fatigue. While the current body of literature addresses a wide range of career fields potentially impacted by trauma, there is a dearth of research related to the potential for trauma work to impact members of the academe. Despite the fact that many higher education faculties are teaching topics related to violence, crime and death, and a subset of this group are also researching and writing on these potentially distressing topics, little attention has been paid to the emotional well-being of professors and scholars. This paper seeks to fill the gap in research related to experiences of vicarious and secondary trauma in higher education by analyzing the personal story of a faculty member working in the field of violence against women. This autoethography will highlight the potential challenges faculty members face when teaching, researching and writing about trauma. Recommendations for addressing trauma within institutions of higher education are offered, and suggestions for future research are discussed.
\end{abstract}

Keywords Sexual violence - Vicarious traumatization - Compassion fatigue $\cdot$ Higher education · Autoethnography

Vicarious traumatization (VT) is a term used in the human service and counseling fields that can be usefully understood as "harmful changes that occur in professionals' view of themselves, others, and the world as a result of exposure to the graphic and/or traumatic material of their clients" (Baird and Kracen 2006 p.181). In response to working with survivors of trauma, VT impacts a caregiver's underlying beliefs in five areas: trust, safety, control, esteem, and intimacy. Secondary traumatic stress (STS) (Figley 1983), also known as compassion fatigue (Figley 1995), is similar to VT, and all three terms are often used interchangeably (although

Andrea Nikischer

nikiscab@buffalostate.edu

1 SUNY Buffalo State, 312-E Bacon Hall, 1300 Elmwood Avenue, Buffalo, NY 14222, USA 
notable differences exist). STS refers to the development of symptoms similar to those of posttraumatic stress disorder (PTSD) through the process of working with trauma survivors. "Professionals who listen to reports of trauma, horror, human cruelty and extreme loss can become overwhelmed and may begin to experience feelings of fear, pain and suffering similar to that of their clients" (Gentry 2002 p. 41). Three main symptom categories exist: (1) reexperiencing the survivor's trauma, (2) avoidance of and/or numbness to the trauma, and (3) persistent arousal. The only marked difference between PTSD and STS is that PTSD is experienced by a trauma survivor and STS is experienced by a person who works with a trauma survivor and/or trauma stories (Jenkins and Baird 2002).

Myriad research has found a relationship between working with potentially distressing situations and content, such as that related to child sexual abuse, sexual assault and domestic violence, and the experience of vicarious or secondary trauma symptoms. While the majority of this research has focused on the experiences of those in the counseling, social work and health professions fields, recent studies have looked beyond these spaces to other arenas where people interact with trauma victims and trauma stories. For example, Maguire and Byrne (2017) found that criminal lawyers exposed to traumatic material in their work are at risk for vicarious traumatization. The authors assert that the vulnerability to VT found in lawyers is a result of organizational factors specific to the work. Lee (2017) argues that probation practitioners who work with traumatized clients are also at risk of developing vicarious traumatization. She advocates for research to confirm this link and for an "enhanced focus" on probation practitioners' emotional well-being (p.382). Similarly, Hendron et al. (2012) contend that members of the clergy are at risk for secondary traumatic stress due to their exposure to trauma stories and traumatic situations. The authors call for rigorous research on the impact of trauma on clergy. Hanrahan et al. (2018) extend the notion of trauma work beyond those working with human beings. They assert that veterinarians and veterinarian technicians are also at risk for secondary traumatic stress in their work. They call for trauma research to include a focus on STS within animal care fields.

While the current body of literature addresses a wide range of career fields potentially impacted by vicarious traumatization and secondary traumatic stress, there is a dearth of research related to the potential for trauma work to impact members of the academe. Despite the fact that many higher education faculties are teaching topics related to violence, crime and death, and a sub-set of this group are also researching and writing on these potentially distressing topics, little attention has been paid to the emotional well-being of professors and scholars working in higher education. Academic programs in social work, counseling and certain health professions frequently address the potential for trauma topics and stories to negatively impact clients and students, but the focus is rarely turned to members of the faculty. Outside of these fields, there is often a complete lack of understanding that traumatic topics have the potential to cause harm.

\section{Autoethnography}

This paper seeks to fill the gap in research related to experiences of vicarious and secondary trauma in higher education by focusing specifically on my personal story as a researcher and faculty member working with issues related to violence against women. The method utilized to inform this article is autoethnography. 
They [autoethnographers] treat their own lived-through experiences as primary data and sites of moral responsibility ... they reveal themselves to themselves, and to you, seeking a perspective on their experiences that neither they nor you had before they did autoethnography. As auto-ethnographers, these writers integrate emotional, spiritual, and moral parts of themselves with the intellectual and analytical ... (Ellis and Bochner 2017, p. vii).

As a faculty member working with traumatic content related to sexual and interpersonal violence, I will share my story with a focus on the ways that researching, writing and teaching violence has impacted my emotional well-being and my ability to meet my professional responsibilities. I wrote reflective journals on my experiences in 2007, 2010 and 2017. Excerpts from these journals along with descriptions of my personal experiences provide evidence of my struggles.

\section{Validity}

Autoethnography does not attempt objectivity. Indeed, autoethographers acknowledge that all research is in some ways influenced by personal choice, preference, and position (Ellis et al. 2011). Instead of objectivity, autoethnographers seek validity through thick descriptions of lived experience. "For autoethnographers, validity means that a work seeks verisimilitude; it evokes in readers a feeling that the experience described is lifelike, believable, and possible, a feeling that what has been represented could be true" (p. 282).

\section{My story}

I was 21 when I began working in the field of violence. I'd carry a pager on weekends and respond to emergency room calls of child sexual abuse, rape or domestic violence. I was a volunteer at first. There were a few calls each month, brief paperwork and I always went to the hospital with a partner. We held the hands of victims in the immediate aftermath of abuse, helping them to understand the medical and legal processes and making clear that the crime committed against them was not their fault. It was important work and I knew that it mattered. Eventually I decided to leave my career in banking to work for the crisis center full time. I thought it was my dream job. I quickly learned that there is a big difference between being a part-time volunteer and being a full-time worker in the field of violence against women.

The first two months at Crisis Services I cried every day. I cried in the bathroom at work, in my car on the ride home, in line at the grocery store, and in bed at night. I cried all the time, about everything. I started to believe the tears would never stop. And then one day they did. I didn't cry again for two years. Not one tear. Not for any reason. That's how it goes with the work. It numbs something inside of you.

(Nikischer personal journal 2007)

When I began my fulltime position at Crisis Services one of the first issues I was informed of was the potential for the work to cause distress. The management at the crisis center understood the risks inherent in being immersed in the lives and stories of survivors of sexual, physical and emotional abuse. The concept of vicarious traumatization (Pearlmann and Saakvitne 1995) had recently gained notice in the counseling and mental health fields and there was a clear attempt to prepare workers to understand the potential impact trauma work 
may have on their emotional health and work productivity. I read articles about the symptoms and met weekly with a supervisor who asked about my feelings, my fears, and my needs. At one point I was shifted from a 5-day work schedule to a 4-day work schedule in order to reduce the daily burden of violence. There was a clear focus in the organization on protecting and caring for the caregivers. There was support from colleagues, too. We were together at work and at happy hours after work. We laughed and we got angry and we kept going. It was not easy work, but the supportive structure in place helped to make it bearable.

I stayed with the crisis center for 3 years. The final year I accepted a small promotion to work as the rape/domestic violence crisis counselor embedded in a suburban police department. On Mondays my first task was to read through the large stack of police reports from the weekend, each one with an accompanying photo of a woman or child who had been raped, assaulted or abused. It was a weekly routine.

I remember going in to work that day. It was a regular Monday morning. I was reading through the reports, and talking on the phone with my friends back at the main office, and I was filing my nails. And I felt nothing. Nothing. Even the photos of bruised and beaten women gave me nothing. When I hung up the phone something clicked. I remember gasping. I saw myself. I knew that something was profoundly wrong with me. I no longer cared. I didn't seem to have the capacity anymore. That night I began applying for other jobs.

(Nikischer personal journal 2007)

As much as I appreciated the powerful impact my work had on the survivors I served, and as much as I enjoyed the supportive and collegial work environment, I had come to see the damaging effect trauma work was having on my emotional state and on my ability to be successful in my job. While it is difficult to be productive when you are drowning in empathy and fear, it is also hard to be successful when you feel nothing. At the time I recognized only a sense of being "wrong," but I can now see many of my specific symptoms were common to trauma work. Osofsky et al. (2008) outline symptoms of "secondary traumatization" in child welfare workers. Reflecting back I can identify having experienced several of the symptoms on their list, including anger, irritability, anxiety, a sense of numbness, sadness, difficulty sleeping and the use of alcohol to "forget about work" (p.93). Even though the crisis center had built in protections, I was unable to avoid vicarious traumatization and compassion fatigue.

\section{Finding hope}

After I left Crisis Services, I went on to be the education coordinator for the Citizens Committee on Rape, Sexual Assault and Sexual Abuse. It was still work in the field of violence, but the focus on prevention gave me something I was missing in my previous work: hope. I recognized the power of education to prevent violence and uplift oppressed communities. This marked an important transition point in my career as I moved from direct service to prevention education. It was, quite frankly, a relief. I still worked for an organization aware of the risks of vicarious traumatization and I still had supportive colleagues, but the work itself was step removed from the individual trauma. In an administrative position, I spent only a small part of my day engaging with the trauma content. In many ways it represented an optimal work environment as I was able to feel a sense of accomplishment that I was working in the field of preventing violence against women and children, but I was relieved of many of the symptoms of secondary traumatic stress. 


\section{Researching violence}

Eventually, I stepped away from violence and moved into administrative work on a healthcare access grant in higher education. I dropped out of my volunteer activities in the field of violence against women and I moved on with my education and career. After a 5-year break from working with violence, I was offered an adjunct teaching position in the Women's Studies Department at our local university. The course was Violence in a Gendered World. At the time, I was working full-time at the University and had just began a $\mathrm{PhD}$ program in education. I understood that an adjunct teaching position would be an important addition to my curriculum vitae and I was excited to get back to the work of teaching about violence. I knew my schedule would be hectic, but I was determined to do it all.

I found myself feeling agitated. I was busy: work, school, teaching, research. It was a lot. But this feeling wasn't busy. It was a fly buzzing behind my back, a nagging distraction keeping me up at night, a sour pit in the stomach, the grinding of teeth. I had had this feeling before.

(Nikischer personal journal 2007)

A few weeks into teaching, I began to notice a general feeling of agitation. Something was bothering me, but I wasn't quite sure what it was. In my PhD program, I had started working on a qualitative research project at the same time I was teaching the course on violence. While most of my peers were working with projects on teaching and learning, I decided to interview survivors of sexual assault about their experiences post-abuse. In both my teaching and my research I found myself completely isolated. As an adjunct instructor teaching a night course, I had little to no interaction with department faculty or staff. No one checked in on me during any point in the semester. The situation was similar with my research. Not only did my peers not understand the work I was doing, several became hostile toward me and the work when it became clear that my findings were unfavorable to teachers and administrators in K-12 schools.

This was a completely different context than the one in which I served survivors at the crisis center or provided prevention education at the Citizen's Committee on Rape. As an adjunct instructor and $\mathrm{PhD}$ student researcher, I felt misunderstood and alone in my work. The Sexual Violence Research Initiative (SVRI) has created specific guidelines to help protect sexual and interpersonal violence researchers from vicarious traumatization (2015). These guidelines recognize the organizational risk factor of "working in isolation." The lack of support during the research phase of my work exacerbated my feelings of agitation, anxiety and fear (both that I would experience personal physical harm and that I would emotionally harm my participants in the course of the work).

Researchers have argued that supportive supervision is a key strategy for mitigating the negative impact of exposure to trauma. "Clinical supervision is considered both a preventative and a coping strategy in ameliorating vicarious traumatization. It helps in improving the personal psychological state of the professional and consequently enhances professional performance" (Peled-Avram 2017 p.30). At the crisis center participation in formal supervision was required and daily informal "check-ins" between supervisors and staff were conducted. Supervision was valued by the organization, and as an employee I found value in it. The situation with higher education faculty is different. 
I think of the night I left Kim's house often. I had spent over two hours with her as she shared the intimate details of her experiences with child sexual abuse. When I left, it was dark and cold. She lived on a quiet suburban street, but I felt the need to run to my car and lock the doors immediately upon entry. As a Rape and Sexual Assault Victim Advocate I had been trained to recognize how I might be impacted by my interactions with survivors. I was taught to be aware of how their experiences of trauma could cause me to feel stress and distress. I was reminded that I am, after all, only human, and not immune to pain of those I seek to help. But I hadn't prepared for my emotional response to Kim's story. No one asked me to "be careful" when I went to her home and no one asked me if I was alright when I returned. No one was watching me to be certain that I remained physically and emotionally healthy. There was no peer or supervisor to talk with. I was completely alone in my interactions with Kim. It was different than all of the other times that I went to the home of a survivor to provide crisis counseling and support, because I went to Kim's home not as an advocate, but as a researcher. I wasn't there to help. I was there to study. (Nikischer personal journal 2010).

Perry et al. (2004) note, "The inevitably human nature of social research means that all researchers will have degrees of emotional involvement in their subject of study" (p. 139), and Sword (1999) reflects, "We cannot separate self from those activities in which we are intimately involved" (p. 277). While researchers are not counselors, the act of ethnographic interviewing, particularly about traumatic experiences, can be an emotional experience for both researcher and researched. Whitt-Woosley and Sprang (2018) found that conducting qualitative research on trauma is a significant risk factor for secondary traumatic stress, and this risk "... seems related to these researchers' experiences of increased exposure to traumatic material, more engagement with research subjects, and increased exposure to other stressful conditions when working in the field" (p. 482).

Despite the risks, qualitative researchers receive no training to effectively address the emotional aspects of our work. Woodby and colleagues, for example, note that "unlike the work of helping professionals, the work of qualitative research is not a therapeutic endeavor; instead, it is a strategic enterprise with the goal of gathering data from informants" (Woodby et al. 2011 p. 835). I felt that in a very visceral way during my interview with Kim. In my previous work I offered the survivors I worked with something meaningful to them, such as counseling, advocacy, information and/or referrals. With Kim the situation was different. She was giving to me, and I was taking her story to inform my research. She was helping me to get my $\mathrm{PhD}$, but I did not feel like I was giving her anything in return.

The SVRI identified "researcher guilt and discomfort" as an individual risk factor for vicarious traumatization.

Researchers may feel guilty that they are not able to directly assist research participants in spite of their many needs, whilst at the same time researchers personally and professionally benefit from the research data and participants' personal stories of trauma. This conflict and unresolved feelings of guilt can increase researcher stress and may contribute to trauma (2015 p. 8).

At a practical level, unlike therapeutic helping professionals who offer their clientele a valuable, concrete set of services to improve their health and well-being, qualitative researchers find themselves in the position of taking time, energy, and personal stories from 
participants while offering little to their participants. This can leave the researcher feeling helpless. For me, this notion that I was taking from women who had already been victimized was deeply troubling. It compounded the feelings of distress and intensified my symptoms of vicarious traumatization. Whereas therapeutic professionals can potentially see their work directly benefit their clientele, qualitative researchers generally exit from their sites with the hope that the data will someday contribute to larger structural changes that will benefit all of society. While this is a noble imagined purpose to be sure, the promise of the potential for positive change years down the road does little to help a researcher sleep at night.

\section{Writing violence}

After completing the research study with survivors of sexual assault, I began the process of trying to write. A clause in the Institutional Review Board (IRB) ${ }^{1}$ protocol required me to transcribe all of the interviews myself and to destroy the audio tapes within 1 month. Kiyimba and O'Reilly (2016) argue that transcriptionists are at risk for emotional harm and potentially vicarious traumatization due in part to the "repeated listening" of trauma stores (p. 468). I personally found myself overwhelmed with the intensity of the transcription process, as reliving each interview created a new source of stress and distress. The coding process that followed offered an additional challenge and I found myself dreading the work. I knew that the interviews were powerful and that the survivors' stories were important and urgent, but I found it hard to write. I was constantly distracted from the work. Even when I was provided an opportunity to write a manuscript for a top-tier journal, I just could not get it done.

Pacing, pacing pacing, I'm wearing a path on my floors. I can't listen. I can't read. I can't think. I just want to walk away from it. More pacing. I just can't sit and write.

(Nikischer personal journal 2010).

Qualitative researchers within the health field have written extensively about their experiences of serious distress while conducting research on "sensitive" topics (see Iocolano 1994; Rager 2005a, b; Woodby et al. 2011). For example, both Rager (2005b) who writes on the emotional challenges encountered while conducting interviews with breast cancer patients and Woodby et al. (2011) who discuss the practice of coding emotionally laden interview data with families of deceased war veterans, found their research was complicated by their own emotional reactions. These authors strongly assert the need for increased levels of preparation and self-care in managing emotional responses "that parallel those of participants" (Woodby et al. 2011 p. 835) during the gathering and analysis of qualitative data. My experience supports their assertions.

"During the coding process, we discovered that we were struggling with the tension between protecting ourselves from the emotional impact of the interviews and listening to and hearing the participants' stories of loss" (Woodby et al. 2011 p. 833). Indeed, researcher distress, often mimicking the distress of participants, has the potential to negatively impact the researcher and the research itself. In the case of my work I found myself stuck, seeking ways to avoid the impact of the trauma stories, during both the analysis and writing phases. It is

\footnotetext{
${ }^{1}$ An Institutional Review Board is a committee at a university or organization that reviews proposed research projects to ensure ethical protections for human participants are in place. IRB oversight in the USA is conducted by the Office for Human Research Protections (OHRP), an office within the US Department of Health and Human Services (American Psychological Association 2018). Ethical Review Boards and Research Ethics Boards serve the same function as an IRB.
} 
imperative during qualitative data analysis for the researcher to be present in the process, as the researcher is the tool of analysis. The scholarship cannot get done without the researcher becoming fully embedded within the data, but when the data are trauma stories there is a risk for vicarious or secondary trauma. This risk is intensified when the researcher is a faculty member who is also teaching and providing service on topics related to trauma.

\section{Teaching violence}

Faculty members who research and write about trauma often teach about trauma, as well. It is a goal as a faculty member to establish expertise in an area of scholarship. This expertise is then called upon in both teaching and service. For example, I research and write about sexual violence, developed and teach a course on interpersonal violence, I speak on sexual and domestic violence at campus and community events, and I facilitate the sexual assault prevention education sub-committee of the Campus Safety Forum. Violence and trauma are embedded in nearly all of my work. While it is possible that I might have the ability to change these commitments once I receive tenure, as an untenured faculty member I never feel that I am in a position to say no.

They asked me to speak at a film series on sexual assault. It is an honor to be considered a campus expert on these issues. And when you are untenured you don't have the privilege of turning down honors. I thought I would prepare by watching the film in advance. It was a mistake. Watching it once was bad. Watching it twice: unbearable. A few minutes before it ended I had to get out of the auditorium. I couldn't breathe. I ran up the aisle and burst out the doors. Finally, air. When I came back I went on stage and answered questions about rape for the next hour. I needed to list that invited presentation on my CV. I didn't have the luxury of worrying about how I felt.

(Nikischer personal journal 2017)

While scholars have examined the potential for distress when researching potentially sensitive topics, there is limited research related to the potential for distress when teaching about trauma. Previous research has stressed the need to be sensitive to the emotional needs of students when teaching, with some authors advocating for a "trauma-informed educational practice" (Carello and Butler 2015), but there is a gap in research related to the potential for vicarious or secondary trauma among those who teach about violence and other trauma-related topics.

In my role as a tenure-track faculty member I feel the same level of isolation in my work as I did as an adjunct instructor and $\mathrm{PhD}$ student researcher. No one in my department works with or teaches about sexual or interpersonal violence and I have no connection with the social work department on campus. My isolation is in part a product of the topic area I teach and also a product of the nature of a faculty position in higher education. Faculty members do not receive direct supervision and often complete their work alone. I create and teach my own lessons and set my own research and writing agenda. No one checks in on me or my work until the end of the year when I file my annual report. That report is submitted electronically and I receive no feedback on it. It is important to note that this isolation does not bother me when I am teaching research methods, grant writing or even diversity. It is the combined burden of teaching, producing scholarship and providing service on the topic of violence that becomes overwhelming. I often find myself feeling like I did when I was a PhD student and adjunct instructor: misunderstood and alone. This takes a toll not only on my emotional well-being, but also on my ability to do the work. 


\section{Limitations and future research}

It is important to acknowledge that my story offers just a small glimpse into the potential for researcher distress and the experience of vicarious trauma within higher education. Singleauthored autoethnographies have limited value as the data are generated and analyzed through one lens. This lack of distance between research participant and researcher is a valid point of concern (See Lapadat 2017).

Although imperfect, this autoethnography does indicate an urgent need for additional research into the experiences of faculty members who research, write and teach about trauma. A collaborative autoethnography would be a positive next step as it would build upon the work presented here while providing a more dynamic analysis of participant experiences (Lapadat 2017). Qualitative interview studies with higher education faculty and with administrators would also provide important insights into the perceptions of faculty and professional staff. Additionally, larger survey studies on and across campuses would provide crucial information about the scope of the problem and institutional willingness to address it.

\section{Recommendations for higher education}

Previous research has taken up the concern of researcher self-care (see Iocolano 1994; Malacrida 2007; Rager 2005a, b; Woodby et al. 2011). While I agree with the recommendations of this body of research, I believe it is imperative that the responsibility for researcher protection goes beyond the individual researchers themselves. Universities and colleges have a stake in ensuring that the research that is conducted is of the highest quality and is undertaken with safety as a primary goal. This notion of safety must broaden to include both the research participants and the researcher. Research funding applications are explicit regarding each minute detail of research methodology and methods, yet nowhere is there any targeted consideration or even mention of the safety and well-being of the researcher. This is problematic most especially for research involving issues of trauma.

Campbell et al. (2009) found that rape survivors want qualitative interviewers to be able to listen to survivors' stories without judgment and without "becoming too engrossed in their own emotions" (p. 607). The survivors recommend that interviewers be prepared in advance to hear the stories of sexual violence and the intense impact such violence can have on survivors' lives. The literature on conducting qualitative interviews with survivors of violence indicates that most interviewers do receive introductory training on violence against women and on how to implement the research protocol (Campbell et al. 2009). However, there is a lack of training focused specifically on the needs of the researcher.

In their study of sexual violence researchers, Coles et al. (2014) found that training for sexual violence research is "an area in need of improvement ..." (p. 110). Woodby et al. (2011) argue for increased training and mentoring for researchers on how to deal with challenging research situations and topics in order to bring about "broad-based, structural level changes to the qualitative process" (p.835). Rager (2005b) offers a similar recommendation, arguing for the need to both alert and prepare novice researchers for the "potentially emotional nature of qualitative research" (p.26). These recommendations are in line with the training promoted in the fields of counseling and social work (See Dane 2002; Sommer 2008), and take the idea of "self-care" out of the hands of the researcher, thereby rendering it a collective concern. 
Training and mentoring for faculty members and research assistants who conduct research on trauma issues can be provided at a system level, a campus level or at an academic school level. In research specific to sexual and interpersonal violence, experts from the local rape crisis center or domestic violence shelter might be called upon to share their experience and knowledge. There may also be opportunities to collaborate with the campus Title IX Coordinator or campus office in charge of responding to reports of sexual misconduct.

While requiring training in compassion fatigue and researcher self-care will add an additional bureaucratic layer to the research process, it does not have to create an undue burden on campuses or faculty. Such training does not need to be exhaustive. The goal should be to ensure that researchers enter their research sites with an awareness of the potential for distress and an understanding of strategies for addressing such distress should it arise. This training will likely take different forms depending on the specific needs and available resources at each institution. In large public systems like the State University of New York (SUNY) a standard training module could be created for all faculty members working with trauma. This training could be delivered in person on individual campuses or via an online platform such as Blackboard.

The participants in my qualitative study of the self-directed learning of breast cancer patients were protected carefully. I met all the requirements of the institutional review board [sic] to conduct the study and to obtain clearance to proceed with data collection via personal interviews with breast cancer patients. Before each interview began, I carefully explained the study and had each woman sign the required informed consent form [...] The question that was not asked as I began my study but that I wish to raise at this time is whether researchers should not also attend to themselves in the process. No thought was given to ensuring that I would take steps to address the impact on me as I conducted such emotionally laden research (Rager 2005a, p. 423).

Although providing training on the potential for researcher distress will be a positive first step, more needs to be done to embed researcher protections into the broader academic research structure. Universities and colleges already have a system in place to insure the protection of research participants. IRBs require detailed participant protection protocols to ensure that each step of the research process is being conducted with the participants' safety and well-being at the forefront. Such protocols must be forwarded to funding agencies upon receipt of a grant and IRB approval is typically required for publication in an academic journal. Because this protection mechanism currently exists at colleges and universities it makes sense to utilize this structure to build protections for the researcher, as well. "The primary function of ethical review boards is to protect the rights and welfare of research participants. Ensuring the wellbeing of researchers and their team should be included in this mandate to ensure that quality research is conducted" (SVRI 2015 p.15).

The SVRI recommends that IRBs add a section to their research protocols for a description of how the researcher/research team will be protected and what steps the researcher/research team will take if they encounter distress.

For research protocols to pass ethical review by ethics boards, it should be an essential requirement that researchers reflect on how they will protect themselves and the research team from or mitigate the risk of vicarious trauma. They should also outline measures and/or strategies that they will implement to ensure this, and budget accordingly ( 2015 p.15). 
My experiences outlined in this autoethnography provide support for these recommendations. Researchers must have a plan in place in advance in order to appropriately handle distress if/ when it arises while working in the field or during the data analysis stage.

Lastly, academic institutions must consider the potential impact of teaching and providing service on issues related to sexual and interpersonal violence and other forms of trauma. Faculty members who work with trauma do not do work that is in any way intellectually more challenging than their peers. However, it can be argued that trauma work is more challenging emotionally. For this reason institutions of higher education must thoughtfully consider and plan for teaching load and service requirements for faculty who do trauma work. This is especially true for untenured or contract faculty who often are not in a position to set limits on their own responsibilities and ensure their own self-care. Administrators, including department chairs and deans, must recognize that the cumulative burden of trauma exposure impacts the likelihood of vicarious or secondary trauma symptoms. It may be reasonable to provide faculty members with a course release or waiver from campus service when they are teaching, researching or writing about trauma. This is just one possible approach. Future research should explore what specific types of teaching and/or service accommodations might be appropriate for faculty members who work with trauma topics.

Taken together, these recommendations - improving training for qualitative researchers working with trauma survivors and potentially traumatic topics, requiring ethical protections for trauma researchers, and limiting teaching and/or service loads for faculty who work with trauma - will provide a solid foundation for reducing the risk for vicarious and/or secondary trauma among faculty. Significantly, these changes will also raise awareness to the issue of the potential for vicarious traumatization within the academe.

\section{References}

American Psychological Association. (2018). Frequently asked questions about Institutional Review Boards. http://www.apa.org/advocacy/research/defending-research/review-boards.aspx.

Baird, K., \& Kracen, A. C. (2006). Vicarious traumatization and secondary traumatic stress: A research synthesis. Counselling Psychology Quarterly, 19(2), 181-188.

Campbell, R., Adams, A. E., Wasco, S. M., Ahrens, C. E., \& Sefl, T. (2009). Training interviewers for research on sexual violence: A qualitative study of rape survivors' recommendations for interview practice. Violence Against Women, 15(5), 595-617. https://doi.org/10.1177/1077801208331248.

Carello, J., \& Butler, L. D. (2015). Practicing what we teach: Trauma-informed educational practice. Journal of Teaching in Social Work, 35(3), 262.

Coles, J., Astbury, J., Dartnall, E., \& Limjerwala, S. (2014). A qualitative exploration of researcher trauma and researchers' responses to investigating sexual violence. Violence Against Women, 20(1), 95-117. https://oi. org/10.1177/1077801213520578.

Dane, B. (2002). Duty to inform: Preparing social work students to understand vicarious traumatization. Journal of Teaching in Social Work, 22(3/4), 3-20.

Ellis, C., Adams, T. E., \& Bochner, A. P. (2011). Autoethnography: An overview. Historical Social Research/ Historische Sozialforschung, $36(4$ (138)), 273-290.

Ellis, C., \& Bochner, A. P. (2017). Foreword. In S. L. Pensoneau-Conway, T. E. Adams, \& D. M. Bolen (Eds.), Doing ethnography. Rotterdam: Sense Publishers.

Figley, C. R. (1983). Catastrophes: An overview of family reactions. In C. R. Figley \& H. I. McCubbin (Eds.), Stress and the family: Vol. 2. Coping with catastrophe (pp. 3-20). New York: Brunner/Mazel.

Figley, C. R. (1995). Compassion fatigue: Coping with secondary traumatic stress disorder in those who treat the traumatized. New York: Brunner/Mazel.

Gentry, J. E. (2002). Compassion fatigue: A crucible of transformation. Journal of Trauma Practice, 1(3-4), 3761. https://doi.org/10.1300/J189v01n03_03. 
Hanrahan, C., Saba, B. M., \& Robb, P. (2018). Secondary traumatic stress and veterinarians: Human-animal bonds as psychosocial determinants of health. Traumatology, 24(1), 73-82.

Hendron, J. A., Irving, P., \& Taylor, B. (2012). The unseen cost: A discussion of the secondary traumatization experience of the clergy. Pastoral Psychology, 61(2), 221-231. https://doi.org/10.1007/s11089-011-0378-z.

Iocolano, C. F. (1994). A qualitative study of four women during the first four months after surgery for breast cancer. Dissertation Abstracts International, 55-09, 3816B.

Jenkins, S. R., \& Baird, S. (2002). Secondary traumatic stress and vicarious trauma: A validational study. Journal of Traumatic Stress, 15(5), 423-432. https://doi.org/10.1023/A:1020193526843.

Kiyimba, N., \& O'Reilly, M. (2016). The risk of secondary traumatic stress in the qualitative transcription process: A research note. Qualitative Research, 16(4), 468-476.

Lapadat, J. C. (2017). Ethics in autoethnography and collaborative autoethnography. Qualitative Inquiry, 23(8), 589-603. https://doi.org/10.1177/1077800417704462.

Lee, R. (2017). The impact of engaging with clients' trauma stories: Personal and organizational strategies to manage probation practitioners' risk of developing vicarious traumatization. Probation Journal, 64(4), 372387. https://doi.org/10.1177/0264550517728783.

Maguire, G., \& Byrne, M. K. (2017). The law is not as blind as it seems: Relative rates of vicarious trauma among lawyers and mental health professionals. Psychiatry, Psychology and Law, 24(2), $233-211$. https://doi.org/10.1080/13218719.2016.1220037.

Malacrida, C. (2007). Reflexive journaling on emotional research topics: Ethical issues for team researchers. Qualitative Health Research, 17(10), 1329-1339.

Osofsky, J. D., Putnam, F. W., \& Lederman, J. C. S. (2008). How to maintain emotional health when working with trauma. Juvenile and Family Court Journal, 59(4), 91-102.

Pearlmann, L. A., \& Saakvitne, K. W. (1995). Trauma and the therapist: Countertransference and vicarious traumatization in psychotherapy with incest survivors. New York: Norton.

Peled-Avram, M. (2017). The role of relational-oriented supervision and personal and work-related factors in the development of vicarious traumatization. Clinical Social Work Journal, 45(1), 22-32.

Perry, C., Thurston, M., \& Green, K. (2004). Involvement and detachment in researching sexuality: reflections on the process of semistructured interviewing. Qualitative Health Research, 14(1), 135-148.

Rager, K. B. (2005a). Compassion stress and the qualitative researcher. Qualitative Health Research, 15(3), 423-430.

Rager, K. B. (2005b). Self-care and the qualitative researcher: When collecting data can break your heart. Educational Researcher, 34(4), 23-27.

Sexual Violence Research Initiative. (2015). Guidelines for the prevention and management of vicarious trauma among researchers of sexual and intimate partner violence. Pretoria: South Africa.

Sommer, C. A. (2008). Vicarious traumatization, trauma-sensitive supervision, and counselor preparation. Counselor Education and Supervision, 48(1), 61-71.

Sword, W. (1999). Accounting for presence of self: Reflections on doing qualitative research. Qualitative Health Research, 9(2), 270.

Whitt-Woosley, A., \& Sprang, G. (2018). Secondary traumatic stress in social science researchers of traumaexposed populations. Journal of Aggression, Maltreatment \& Trauma, 27(5), 475.

Woodby, L. L., Williams, B., Wittich, A. R., \& Burgio, K. L. (2011). Expanding the notion of researcher distress: The cumulative effects of coding. Qualitative Health Research, 21(6), 830-838. 